\title{
The costs of hepatitis A infections in South Korea
}

\author{
Kyohyun Kim ${ }^{1}$, Baek-Geun Jeong ${ }^{2}$, Moran $\mathrm{Ki}^{3}$, Mira Park ${ }^{4}$, Jin Kyung Park ${ }^{5}$, Bo Youl Choi ${ }^{6}$, \\ Weon-Seob $\mathrm{Yoo}^{7}$ \\ ${ }^{1}$ Research Institute, Health Insurance Review \& Assessment Service, Seoul; ${ }^{2}$ Department of Preventive Medicine, Gyeongsang National \\ University School of Medicine, Jinju; ${ }^{3}$ Department of Cancer Control and Policy, Graduated School of Cancer Science and Policy, National \\ Cancer Center, Goyang; ${ }^{4}$ Department of Preventive Medicine, Eulji University School of Medicine, Daejeon; ${ }^{5}$ International Vaccine Institute, \\ Seoul; ${ }^{6}$ Department of Preventive Medicine, Hanyang University College of Medicine, Seoul; ${ }^{7}$ Regional Cardiocerebrovascular Center, \\ Chungnam National University Hospital, Daejeon, Korea
}

OBJECTIVES: The incidence of hepatitis A infections among young adults has recently increased in South Korea. Although universal vaccination has often been suggested to mitigate the problem, its rationale has not been well-understood. Estimating the societal costs of hepatitis A infections might support the development of intervention strategies.

METHODS: We classified hepatitis A infections into eight clinical pathways and estimated the number of occurrences and cost per case for each clinical pathway using claim data from National Health Insurance and several national surveys as well as assumptions based on previous studies. To determine the total costs of a hepatitis A infection, both direct and indirect costs were estimated. Indirect costs were estimated using the human-capital approach. All costs are adjusted to the year 2008.

RESULTS: There were 30,240 identified cases of hepatitis A infections in 2008 for a total cost of 80,873 million won (2.7 million won per case). Direct and indirect costs constituted $56.2 \%$ and $43.8 \%$ of the total costs, respectively. People aged $20-39$ accounted for $71.3 \%$ of total cases and $74.6 \%$ of total costs. Medical costs per capita were the lowest in the 0-4 age group and highest in the 20-29 age group.

CONCLUSIONS: This study could provide evidence for development of cost-effective interventions to control hepatitis A infections. But the true costs including uncaptured and intangible costs of hepatitis A infections might be higher than our results indicate.

KEY WORDS: Cost of illness, Hepatitis A, Infection, Republic of Korea

\section{INTRODUCTION}

Hepatitis A is an acute infectious disease that exhibits symptoms including jaundice, fever, and loss of appetite. In general, the disease spreads through human-to-human, foodborne, and

Correspondence: Weon-Seob Yoo

Regional Cardiocerebrovascular Center, Chungnam National University Hospital, 282 Munhwa-ro, Jung-gu, Daejeon 301-721, Korea

Tel: +82-42-280-8946, Fax: +82-42-280-8946, E-mail: wwssuu@gmail.com

Received: Apr 23, 2014, Accepted: Jul 8, 2014, Published: Aug 18, 2014

This article is available from: http://e-epih.org/

(C) 2014, Korean Society of Epidemiology

(C) This is an open-access article distributed under the terms of the Creative Commons Attribution License (http://creativecommons.org/licenses/by/3.0/), which permits unrestricted use, distribution, and reproduction in any medium, provided the original work is properly cited. waterborne transmission [1]. Over 1.4 million cases of hepatitis A occur worldwide each year. Thus, the economic burdens associated with the disease are estimated to be between $\$ 1.5$ to 3.0 billion per year [2].

Since the 1990s, many countries have faced decreasing natural infection occurrences during childhood because of the increase in socioeconomic and hygiene levels. However, such reduced natural infections also reduced the rate of the hepatitis $\mathrm{A}$ antibodies in the overall population, resulting in an epidemiological transition of increasing hepatitis A susceptibility in adult populations $[1,3,4]$. Contrary to pediatric hepatitis $\mathrm{A}$, adult hepatitis $\mathrm{A}$ is generally presented as a symptomatic infection and can cause death. Therefore, the increase in the number of individuals susceptible to hepatitis $\mathrm{A}$ in the adult population is a looming global public health issue [5]. 
South Korea has also experienced an epidemiological transition of hepatitis A in the past 10 years. Echoing the increasing concern, a significant proportion of the adult population lacks hepatitis A antibodies [6-9]. According to the Korea Centers for Disease Control and Prevention, there were approximately 8,000 hepatitis A incidences in 2008, representing a 20-fold increase compared to 2004. Approximately $80 \%$ of cases in 2008 occurred in the adult population aged between 20 and 39 years. Based on this data, it is clear that responsive hepatitis A intervention strategies must be urgently developed [10].

Although universal vaccination has been suggested as a method for managing hepatitis A in South Korea, evidence in support of a vaccination strategy are currently lacking $[11,12]$.

The present study was conducted to present the socioeconomic costs of hepatitis A in South Korea in 2008 to capture the attention of health authorities and the general public regarding the disease by provding necessary evidences for developing a cost-effective intervention strategy to manage hepatitis A.

\section{MATERIALSAND METHODS}

\section{Research design and data collection}

This study used an incidence-based approach to estimate the economic burden of hepatitis A infections in South Korea in 2008. The incidence-based approach is a method that computes the cost of the disease over the lifecycle of a single incident from the start of the incident to complete recovery or death. This method can be used to estimate the benefit realized when a single occurrence of the disease is prevented $[13,14]$. The disease burden of hepatitis A infections was estimated using the following three steps.

1. We first classified hepatitis A infections into eight clinical pathways and calculated the incidence rate of each clinical pathway by age group. We multiplied this incidence rate by the number of hepatitis A incidences by age group to compute the total number of incidences for each age group and clinical pathway.

2. Then, we segmented the total cost of a single hepatitis A case into direct and indirect costs and computed the cost of a single case for the respective age group and clinical pathway.

3. We multiplied the number of incidences in the respective age group and clinical pathway (outcome of step 1) with the cost of hepatitis A per person (outcome of step 2) to determine the total social cost of hepatitis A.

\section{National Health Insurance claims data}

In order to estimate the number of hepatitis A incidences and their associated costs in a single year (2008) in South Korea, we used National Health Insurance (NHI) claims data. National
Health Insurance Corporation stores the demographic information, diagnostic codes, dates of consultation and treatment, treatment fees, and death records of NHI enrollees through computerized management. If these data are used, it is possible to conduct studies of the cost of a particular disease on a national level. Costs of disease studies regarding asthma, injuries, strokes, and hepatitis B using this data set have already been reported [15-18].

The present study used NHI claims data and identified approximately 80,000 claims of hepatitis A infections (International Classification of Diseases version 10 codes B15, B15.0, B15.9) using primary or secondary diagnostic codes. The claim data were then converted to 30,240 cases of person-based data, which allows measurement of the total treatment period and cost for each individual. Because hepatitis $\mathrm{A}$ is a disease that produces immunity after a single infection, each unit of person-based data can be regarded as a single case of hepatitis A.

The data used for analysis were provided by the Health Insurance Review and Assessment Service, which processed the data to encrypt any personal identifiers. All matters associated with the conduct of the present study were approved by the institutional review board (No. 09-09) of Eulji University Hospital.

\section{Hepatitis A incidence rate and number of incidences with respect to age group and clinical pathway}

The present study is based on a previous study in that it categorized hepatitis A infections in eight mutually exclusive clinical pathways depending on the status of hospitalization, fulminant hepatitis incidence, liver transplantation, and death (Figure 1). Clinical pathways I and II are hepatitis A infections that were cured only through outpatient treatment. Pathway I indicates visits to a clinic, whereas pathway II indicates visits to a hospital. Clinical pathways III and IV are cases in which patients had survived and died, respectively, after being hospitalized because of non-fulminant hepatitis. Clinical pathways V andVI are cases in which patients had survived and died, respectively, after being hospitalized because of fulminant hepatitis but were not able to receive liver transplantations for various reasons. Clinical pathways VII and VIII are cases in which patients had survived and died, respectively, after being hospitalized because of fulminant hepatitis and receiving liver transplantations.

The incidence rate of the respective clinical pathways can be calculated by multiplying the probabilities at points where the respective clinical pathways bifurcate (Figure 1). For example, if the probabilities of hospitalization because of hepatitis A, fulminant hepatitis incidence in an inpatient, liver transplantation for inpatients with fulminant hepatitis, and survival for patients that had received the liver transplantation are known, the probability at each step can be multiplied to compute the incidence rate of clinical pathway VIII in a hepatitis A patient. NHI claims data 


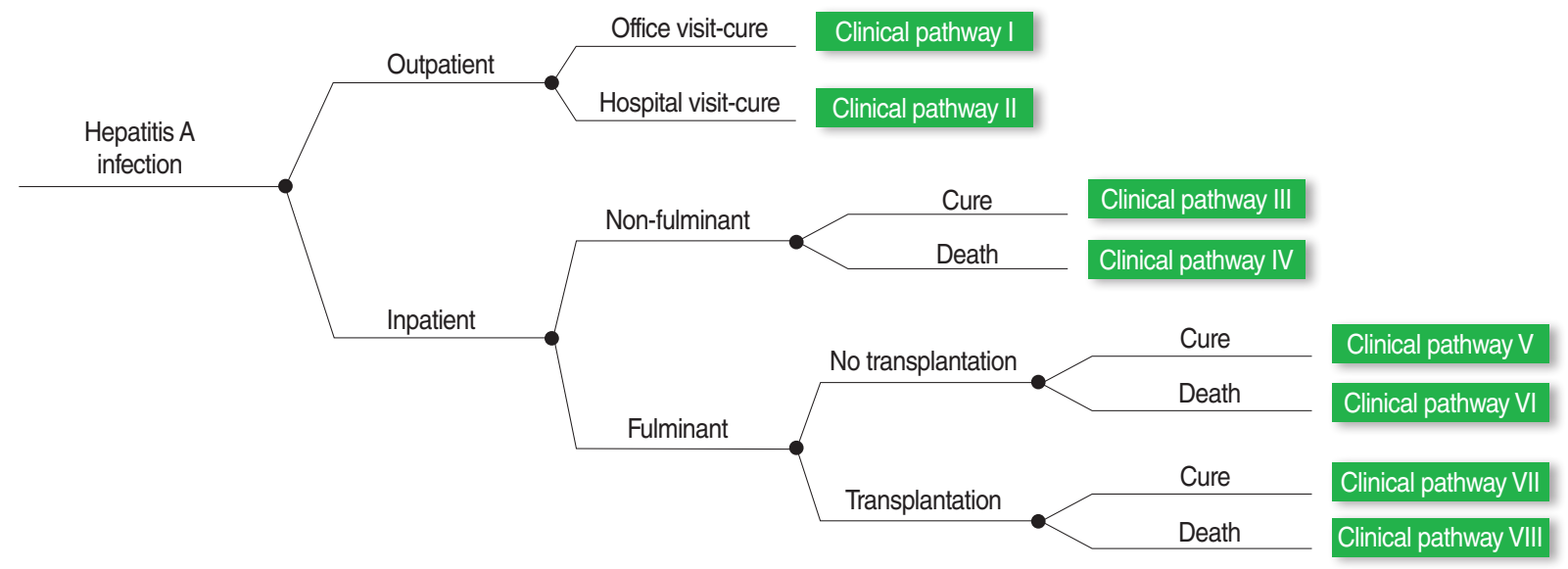

Figure 1. Eight clinical pathways model of hepatitis A infections.

and precedent study results were used to compute the probabilities at each bifurcation point for the respective age groups. In the case that probabilities for each age group could not be computed, we assumed that the probabilities at a given bifurcation point were the same for all age groups.

The probability of an outpatient visit (clinic, hospital) and the probability of hospitalization with respect to each age group were computed using NHI claim data. The incidence rate of fulminant hepatitis for inpatients was set to $1.1 \%$ as reported by Bauch et al. [19], because no domestic data were available. The liver transplantation rate of fulminant hepatitis patients $(37.1 \%)$, case fatality rate of liver transplantation patients $(23.1 \%)$, and case fatality rate of patients that did not receive liver transplantations $(9.1 \%)$ were reported from domestic study results [20]. The probability of death for a non-fulminant hepatitis patient was computed by subtracting the probability of death for a fulminant hepatitis patient from the probability of death for a hepatitis patient overall $[20,21]$.

The probabilities calculated in this manner were multiplied by the number of hepatitis A incidences with respect to age groups according to the claims data to compute the number of hepatitis A incidences with respect to age group and clinical pathway. Meanwhile, we computed the incidence rate of hepatitis A with respect to age group using the population data from the Korea National Statistical Office (KOSIS).

\section{Cost of hepatitis A estimation}

The cost of hepatitis A was segmented into direct and indirect costs with respect to age groups and clinical pathways. Direct costs include medical, supplemental care, and transportation costs. Indirect costs included productive losses due to treatment or premature death. All costs were adjusted to 2008 using the June 2008 exchange rate ( 1 USD =1,000 Korean won) and displayed in USD.

\section{Direct cost}

Medical costs were categorized as costs paid by insurance, by patients under copayment, and by patients for services not covered. Costs paid by insurance and by patients under copayment were labeled costs for covered services and computed using claims data and precedent studies. Hepatitis A costs paid by patient for non-covered services were computed using results from "the state of out-of-pocket medical cost burdens of a patient covered by the NHI in 2007" to apply the ratio between "cost paid by the patient for covered services" to "cost paid by the patient for non-covered services" [22]. Meanwhile, NHI claims data used in the present study did not include costs of outpatient medication. Thus, we indirectly computed the total cost of outpatient medication using the number of prescription days, number of visit days, and cost of medication per day in outpatients in the $2007 \mathrm{NHI}$ yearly statistics [23].

Medical costs for clinical pathways I and II were computed by selecting claims that mapped hepatitis A cases without records of inpatient treatment. These medical costs were computed for each age group. The medical costs of clinical pathways III and IV were computed by selecting claims with a hospitalization record, whose medical cost resulting from the disease were below the top $1.1 \%$, and who posted a treatment result of either "survival" or "death." The $1.1 \%$ threshold used in the calculation is based on the results of a preceding study that reported that the proportion of fulminant hepatitis cases in all hepatitis cases is $1.1 \%$ and the assumption that fulminant hepatitis has a higher medical cost than non-fulminant hepatitis does [19].

Medical costs of clinical pathways V and VI were computed by multiplying the number of inpatient days extracted from a domestic precedent study and the daily medical cost of hospitalization computed in clinical pathway III [20]. Thus, the medical costs of clinical pathways V and VI were $\$ 7,157$ and $\$ 9,169$, respectively. 
Medical costs of clinical pathway VII were calculated based on a Korean precedent study associated with liver transplantation costs. Yang et al. [18] reported liver transplantation costs of a hepatitis B patient, and Ha [24] compared liver transplantation costs between hepatitis B patients and other patients. Using this information and accounting for the rise in medical fee schedule, liver transplantation costs for a hepatitis A patient in 2008 was calculated. Using this method, first-year liver transplantation inpatient costs, first-year outpatient costs, and second-year inpatient costs were $\$ 72,850, \$ 4,203$, and $\$ 9,279$, respectively. Thus, the total cost of clinical pathway VII was $\$ 86,332$.

The medical costs of clinical pathway VIII were calculated based on the number of hospitalization days of the transplantation patient and on the medical costs of clinical pathway VII. We first extracted the medical cost per inpatient day using the number of inpatient days spent by a hepatitis A patient that survived after liver transplantation as well as the inpatient costs of clinical pathway VII. Then, we multiplied the computed medical cost per inpatient day by the number of inpatient days spent by a hepatitis A patient that did not survive after liver transplantation to obtain the inpatient cost for a hepatitis A patient that did not survive the liver transplant [20]. Thus, the computed medical costs of clinical pathway VIII were $\$ 40,246$.

The non-medical direct costs of hepatitis A patients included transportation costs and supplemental care costs incurred from providing extra care to inpatients. Transportation costs were calculated by obtaining the sum of inpatient transportation costs and the number of outpatient visit days multiplied by the transportation cost per outpatient visit day, which was calculated in the following manner: First, we used the national database "2005 Korea National Health and Nutrition Examination Survey" to calculate the round-trip cost of an outpatient clinic visit, an outpatient hospital visit, and inpatient transportation. Then, we accounted for the consumer price index (CPI) to calculate transportation costs at the 2008 price level. The outpatient clinic visit and outpatient hospital visit transportation costs were $\$ 5.0$ and \$10.1, respectively. The transportation cost for a hospitalization case was $\$ 23.5$. The calculation of outpatient visit days is explained in the indirect cost calculation method below.

Supplemental care costs are direct costs incurred from providing extra care beyond the scope of care covered by standard medical costs. By accounting for the standard domestic situation regarding supplemental care, we assumed that supplemental care costs are incurred daily in a fixed amount for the duration of inpatient stay $[25,26]$. We set daily supplemental care costs to $\$ 40$ based on the market price in 2008 .

\section{Indirect costs}

With respect to the indirect costs, we used the human capital approach to estimate the cost of productive loss due to hepatitis
A. The cost of productive loss for the duration of the treatment period (because of morbidity) was calculated by multiplying the number of non-productive days because of hepatitis A by the average daily wage. The number of non-productive days was calculated by adding the number of inpatient days and one-third of the number of outpatient visit days $[16,17,25]$.

The number of inpatient and outpatient visit days for clinical pathways I through IV were calculated using NHI claims data. The number of inpatient days for clinical pathways V and VI were set to 18.5 and 23.7 days, respectively, based on previous studies. Outpatient visit days for clinical pathwaysV and VI were computed by multiplying the number of inpatient days by the number of outpatient visit days per inpatient day given by clinical pathway III. As a result, the outpatient visit days of clinical pathways V and VI were 3.2 and 4.1 days, respectively [20]. The number of inpatient days for clinical pathways VII and VIII were 42.9 and 23.7 days, respectively, based on the same aforementioned study. The outpatient visit days of clinical pathway VII were calculated under the assumptions of two outpatient visit days per month for the first 6 months after liver transplantation, 1 day per month for the next 12 months, and no outpatient visits thereafter. Thus, the number of outpatient visit days for clinical pathway VII was calculated as 24.6 days. We assumed that there were no outpatient visit days for clinical pathway VIII. The average daily wage adjusted to 2008 was computed by reformulating the total monthly wage by age group in 2006 to the average wage. Then, we accounted for the rising CPI and employment rate by age group to compute the final average daily wage [27]. Individuals between the ages 15 and 69 were assumed to be engaged in economically productive activities. Average daily wages of a 15 -year old individual was substituted with the average daily wages of a 16-year old, because wage statistics do not evaluate wages earned by 15 -year olds. Furthermore, we used the average daily wage of a 60 -year old individual to account for the average daily wage of individuals between the age of 61 and 69. Productive losses incurred from outpatient visits by individuals under the age of 14 or over the age of 70 were calculated by assuming that the guardian of the aforementioned age groups was a 40 -year old female. Thus, we estimated productive losses by applying the average daily wage and the employment rate of care giver's age group.

The productive losses incurred from premature death (because of mortality) was calculated by estimating the future expected income of the deceased patient under the assumption that he or she would have survived to work until the age of 69 . We considered the average annual wages, employment rate, and natural death rate by age group in 2008 and applied a $5 \%$ annual discount rate to calculate the future expected income in 2008 dollars [27]. The average annual wages by age group in 2008 were calculated by multiplying the 2006 wages provided 
by KOSIS by the increasing annual CPI. The natural death rate was also acquired from KOSIS. Using this methodology, the cost of productive losses for the death of a 30-year old in 2008 was $\$ 378,000$.

Costs of productive loss due to mortality $=\sum_{i=0} \sum_{\tau=0} \frac{N_{\mathrm{i}} \times \mathrm{w}_{\mathrm{i}+\tau} \times \mathrm{e}_{\mathrm{i}+\tau} \times \mathrm{d}_{\mathrm{i}+\tau}}{(1+r)^{\tau}}$

i: age of mortality case

$\tau$ : years after death

$\omega:$ annual wage rate

e: employment rate

$\mathrm{d}$ : natural mortality rate

r: discount rate $(0.05)$

\section{Sensitivity analysis}

In order to perform a sensitivity analysis, we considered the fatality of non-fulminant hepatitis A and the probability of receiving a liver transplantation surgery as a fulminant hepatitis A patient. When the aforementioned metrics changed to $50 \%$ or $150 \%$ of their default values, we presented the change in the magnitude of the hepatitis A cost burden in the results.

\section{RESULTS}

\section{The number of hepatitis A incidences}

The number of hepatitis A incidences in South Korea in 2008 identified by NHI claims data was 30,240 cases. The incidence rate was 62.2 cases per 100,000 individuals (Table 1). There were 10,643 and 10,902 cases for age groups 20-29 and 30-39, respectively, accounting for $71.3 \%$ of the total number of incidences. The incidence rates for age groups for age groups 20-29 and 30-39 were the highest at 148.2 and 131.6 cases per 100,000 individuals, respectively. Regarding the number of incidences by clinical pathway, clinical pathway III (i.e., non-fulminant hepatitis cured through inpatient treatment) was the highest and most common: 18,075 cases accounting for $59.8 \%$ of the total number of incidences. It was estimated that 202 hepatitis A cases had fulminant hepatitis, 75 of which resulted in a liver transplantation surgery.

With respect to the probability of hepatitis A by age group and clinical pathway, the probability of an incidence with clinical pathways III-VIII requiring hospitalization was the highest in the 20-29 age group at $68.8 \%$, followed by the 5-9 and 60 69 age group with probabilities $30.3 \%$ and $25.0 \%$, respectively. The probability of a hepatitis incidence for clinical pathways IV, VI, and VIII, indicating death, was lowest in the 0-4 age group at $0.1 \%$ and highest in the $80-89$ age group at $3.9 \%$.

\section{Cost per hepatitis A case}

The total cost of a single case of hepatitis A, including direct and indirect costs, was $\$ 2,674$. With respect to age group, the total cost per case was the lowest in the 0-4 age group at \$934. By contrast, the total cost per case was highest in the 40-49 age group at $\$ 3,046$ (Table 2). Regarding the clinical pathways, the lowest total costs per case were found in clinical pathways I and II at $\$ 162$ and $\$ 259$, respectively (because of their lack of hospitalization). Clinical pathway VII (i.e., a complete recovery after liver transplantation) imposed a cost of $\$ 91,001$ per case. The costs per case were highest in clinical pathways IV, VI, and VIII (indicating patient death) at $\$ 200,000$. For the most common hepatitis A incidence type (clinical pathway III for the 2029 age group), the total cost per case was $\$ 2,489$.

Within the total average cost of $\$ 2,674$ for a hepatitis A case, direct costs were $\$ 1,502$, where medical costs amounted to $\$ 1,206$.

Table 1. Estimated number of hepatitis A infections by clinical pathways and age groups in South Korea, 2008

\begin{tabular}{|c|c|c|c|c|c|c|c|c|c|c|}
\hline \multirow{2}{*}{ Age (yr) } & \multicolumn{8}{|c|}{ Clinical pathways of hepatitis A infections } & \multirow{2}{*}{ Total } & \multirow{2}{*}{$\begin{array}{c}\text { Incidence } \\
\text { (per 100,000) }\end{array}$} \\
\hline & I & ॥ & III & IV & V & $\mathrm{VI}$ & VII & VIII & & \\
\hline $0-4$ & 55 (21.32) & $114(44.19)$ & $88(34.03)$ & $0(0.09)$ & $1(0.22)$ & $0(0.02)$ & $0(0.11)$ & $0(0.03)$ & $258(0.85)$ & 11.4 \\
\hline $5-9$ & $145(39.94)$ & $108(29.75)$ & $108(29.87)$ & $0(0.09)$ & $1(0.19)$ & $0(0.02)$ & $0(0.10)$ & $0(0.03)$ & $363(1.20)$ & 12.8 \\
\hline $10-14$ & $270(30.79)$ & $197(22.46)$ & $405(46.17)$ & $1(0.07)$ & $3(0.29)$ & $0(0.03)$ & $1(0.15)$ & $0(0.04)$ & $877(2.90)$ & 26.1 \\
\hline $15-19$ & $410(25.18)$ & $387(23.77)$ & $820(50.38)$ & $2(0.10)$ & $5(0.32)$ & $1(0.03)$ & $3(0.16)$ & $1(0.05)$ & 1,628 (5.38) & 49.7 \\
\hline $20-29$ & $1,425(13.39)$ & $1,891(17.77)$ & $7,238(68.01)$ & $8(0.07)$ & $46(0.43)$ & $5(0.04)$ & $23(0.22)$ & $7(0.06)$ & $10,643(35.20)$ & 148.2 \\
\hline $30-39$ & 1,486 (13.63) & 2,230 (20.46) & 7,095 (65.08) & $12(0.11)$ & $45(0.41)$ & $5(0.04)$ & $23(0.21)$ & $7(0.06)$ & $10,902(36.05)$ & 131.6 \\
\hline $40-49$ & $641(18.86)$ & $997(29.34)$ & $1,732(50.95)$ & $9(0.28)$ & $11(0.33)$ & $1(0.03)$ & $6(0.16)$ & $2(0.05)$ & $3,399(11.24)$ & 40.7 \\
\hline $50-59$ & $422(34.34)$ & $481(39.14)$ & $313(25.47)$ & $9(0.77)$ & $2(0.17)$ & $0(0.02)$ & $1(0.08)$ & $0(0.03)$ & $1,229(4.06)$ & 20.4 \\
\hline $60-69$ & $194(32.50)$ & $254(42.55)$ & $139(23.23)$ & $9(1.45)$ & $1(0.16)$ & $0(0.02)$ & $0(0.08)$ & $0(0.02)$ & $597(1.97)$ & 15.6 \\
\hline $70-79$ & 87 (31.64) & $84(30.55)$ & 95 (34.63) & $8(2.77)$ & $1(0.24)$ & $0(0.02)$ & $0(0.12)$ & $0(0.04)$ & $275(0.91)$ & 11.6 \\
\hline $80+$ & $13(19.12)$ & $11(16.18)$ & $41(60.25)$ & $3(3.75)$ & $0(0.41)$ & $0(0.04)$ & $0(0.20)$ & $0(0.06)$ & $68(0.22)$ & 8.2 \\
\hline Total & $5,149(17.03)$ & 6,755 (22.34) & $18,075(59.77)$ & $60(0.20)$ & $115(0.38)$ & $12(0.04)$ & $58(0.19)$ & $17(0.06)$ & $30,240(100.00)$ & 62.2 \\
\hline
\end{tabular}

Values are presented as number (\%). 
Given the same clinical pathway, the total cost of a single case of hepatitis A still differed depending on the age group. In the case of clinical pathway III, the medical cost per case was approximately 1.5 times higher in the age group 20-39 compared to that of the age group $0-4$.

\section{The total cost of hepatitis A}

In the year 2008, the total cost incurred because of hepatitis A incidences was estimated to be approximately $\$ 80,873,000$ (Table 3). Given the total cost of hepatitis, direct and indirect costs accounted for $56.2 \%$ and $43.8 \%$ of the total cost, respectively. Overall, $80.3 \%$ of the direct costs were medical costs, whereas the remaining $19.3 \%$ consisted of supplemental care costs and transportation costs. In total, $59.3 \%$ of the medical costs were paid by health insurance, whereas $40.7 \%$ was paid by the patients. One-third of the indirect costs were productive losses incurred from using the medical services, and the remaining two-thirds of the indirect costs were productive losses incurred from early death.

Clinical pathway III constituted $58.3 \%$ of total costs incurred by hepatitis A, capturing the largest cost among the eight clinical pathways. The total number of outpatient visits because of hepatitis A was 64,031, and the total number of inpatient days was 198,715 (i.e., 544 years).

Table 2. Estimated total costs per capita of hepatitis A infections by clinical pathways and age groups in South Korea, 2008

\begin{tabular}{|c|c|c|c|c|c|c|c|c|c|}
\hline \multirow{2}{*}{ Age (yr) } & \multicolumn{8}{|c|}{ Clinical pathways of hepatitis A infections } & \multirow{2}{*}{$\begin{array}{c}\text { Weighted } \\
\text { average }\end{array}$} \\
\hline & I & $\|$ & III & IV & V & $\mathrm{VI}$ & VII & VIII & \\
\hline $0-4$ & 96 & 197 & 1,390 & 161,044 & 8,006 & 168,904 & 88,734 & 199,871 & 934 \\
\hline $5-9$ & 102 & 185 & 1,664 & 212,308 & 8,006 & 220,168 & 88,734 & 251,135 & 1,002 \\
\hline $10-14$ & 125 & 207 & 1,788 & 268,582 & 8,006 & 276,442 & 88,734 & 307,409 & 1,460 \\
\hline $15-19$ & 131 & 216 & 2,072 & 319,681 & 8,587 & 328,075 & 89,977 & 359,068 & 1,897 \\
\hline $20-29$ & 156 & 224 & 2,489 & 366,602 & 8,822 & 375,221 & 90,592 & 406,197 & 2,677 \\
\hline $30-39$ & 191 & 259 & 2,759 & 376,504 & 9,170 & 385,455 & 91,501 & 416,406 & 2,921 \\
\hline $40-49$ & 174 & 295 & 3,055 & 324,248 & 9,343 & 333,363 & 91,952 & 364,303 & 3,046 \\
\hline $50-59$ & 158 & 346 & 2,806 & 219,468 & 9,266 & 228,510 & 91,751 & 259,455 & 2,785 \\
\hline $60-69$ & 145 & 362 & 2,912 & 90,487 & 9,097 & 99,368 & 91,311 & 130,324 & 2,323 \\
\hline $70-79$ & 131 & 329 & 1,995 & 2,391 & 8,006 & 10,250 & 88,734 & 41,218 & 1,041 \\
\hline $80+$ & 165 & 187 & 2,192 & 2,391 & 8,006 & 10,250 & 88,734 & 41,218 & 1,714 \\
\hline $\begin{array}{r}\text { Weighted } \\
\text { average }\end{array}$ & 162 & 259 & 2,610 & 232,672 & 8,974 & 361,136 & 91,001 & 392,099 & 2,674 \\
\hline
\end{tabular}

Unit: 1 US dollar.

Table 3. Estimated total direct and indirect costs of hepatitis A infections by clinical pathways in South Korea, 2008

\begin{tabular}{|c|c|c|c|c|c|c|c|c|c|}
\hline & \multicolumn{8}{|c|}{ Clinical pathways of hepatitis A infections } & \multirow{2}{*}{ Total (\%) } \\
\hline & 1 & $\|$ & III & IV & V & $\mathrm{VI}$ & VII & VIII & \\
\hline \multicolumn{10}{|l|}{ Direct costs } \\
\hline \multicolumn{10}{|l|}{ Medical costs } \\
\hline Costs paid by health insurance & 356 & 600 & 16,548 & 86 & 562 & 72 & 2,976 & 434 & $21,633(26.75)$ \\
\hline \multicolumn{10}{|l|}{ Costs paid by patients } \\
\hline For covered services & 142 & 486 & 5,707 & 14 & 94 & 12 & 712 & 77 & $7,245(8.96)$ \\
\hline For non-covered services & 37 & 203 & 5,659 & 26 & 169 & 22 & 1,287 & 185 & $7,588(9.38)$ \\
\hline Supplementary care costs & 0 & 0 & 7,722 & 15 & 85 & 11 & 99 & 16 & $7,949(9.83)$ \\
\hline Transportation costs & 64 & 161 & 765 & 1 & 6 & 1 & 16 & 0 & $1,014(1.25)$ \\
\hline Subtotal & 599 & 1,450 & 36,401 & 143 & 917 & 117 & 5,089 & 713 & $45,428(56.17)$ \\
\hline \multicolumn{10}{|l|}{ Indirect costs } \\
\hline Number of outpatient visit & 12,661 & 15,903 & 33,636 & 0 & 367 & 47 & 1,417 & 0 & 64,031 \\
\hline Days of hospitalization & 0 & 0 & 193,044 & 384 & 2,132 & 273 & 2,472 & 410 & 198,715 \\
\hline \multicolumn{10}{|l|}{ Costs of productive loss } \\
\hline Due to morbidity & 234 & 300 & 10,768 & 19 & 118 & 15 & 154 & 21 & $11,630(14.38)$ \\
\hline Due to mortality & $\begin{array}{r}204 \\
0\end{array}$ & 0 & 0 & 13,740 & 0 & 4,030 & 0 & 6,045 & $23,815(29.45)$ \\
\hline Subtotal & 234 & 300 & 10,768 & 13,759 & 118 & 4,045 & 154 & 6,067 & $35,445(43.83)$ \\
\hline Total (\%) & $\begin{array}{r}833 \\
(1.03)\end{array}$ & $\begin{array}{r}1,750 \\
(2.16)\end{array}$ & $\begin{array}{l}47,169 \\
(58.32)\end{array}$ & $\begin{array}{r}13,902 \\
(17.19)\end{array}$ & $\begin{array}{r}1,034 \\
(1.28)\end{array}$ & $\begin{array}{l}4,162 \\
(5.15)\end{array}$ & $\begin{array}{l}5,244 \\
(6.48)\end{array}$ & $\begin{array}{l}6,779 \\
(8.38)\end{array}$ & $80,873(100.00)$ \\
\hline
\end{tabular}

Unit: 1,000 US dollar. 
Table 4. Estimated total cost of hepatitis A infections by clinical pathways and age groups in South Korea, 2008

\begin{tabular}{|c|c|c|c|c|c|c|c|c|c|c|}
\hline \multirow{2}{*}{ Age (yr) } & \multicolumn{8}{|c|}{ Clinical pathways of hepatitis A infections } & \multirow{2}{*}{ Total } & \multirow{2}{*}{$(\%)$} \\
\hline & I & $\|$ & III & IV & V & $\mathrm{Vl}$ & VII & VIII & & \\
\hline $0-4$ & 5 & 22 & 122 & 36 & 4 & 9 & 25 & 17 & 241 & $(0.30)$ \\
\hline $5-9$ & 15 & 20 & 181 & 71 & 6 & 15 & 31 & 26 & 364 & $(0.45)$ \\
\hline $10-14$ & 34 & 41 & 724 & 157 & 21 & 71 & 114 & 119 & 1,280 & (1.58) \\
\hline $15-19$ & 54 & 83 & 1,699 & 519 & 45 & 171 & 235 & 281 & 3,089 & (3.82) \\
\hline $20-29$ & 222 & 423 & 18,016 & 2,801 & 406 & 1,728 & 2,086 & 2,806 & 28,488 & (35.23) \\
\hline $30-39$ & 284 & 578 & 19,575 & 4,367 & 414 & 1,741 & 2,066 & 2,821 & 31,847 & (39.38) \\
\hline $40-49$ & 112 & 294 & 5,290 & 3,070 & 103 & 369 & 509 & 605 & 10,351 & (12.80) \\
\hline $50-59$ & 67 & 166 & 879 & 2,073 & 19 & 47 & 94 & 80 & 3,424 & (4.23) \\
\hline $60-69$ & 28 & 92 & 404 & 784 & 9 & 9 & 43 & 18 & 1,387 & (1.71) \\
\hline $70-79$ & 11 & 28 & 190 & 18 & 5 & 1 & 29 & 4 & 286 & (0.35) \\
\hline $80+$ & 2 & 2 & 90 & 6 & 2 & 0 & 12 & 2 & 117 & (0.14) \\
\hline $\begin{array}{l}\text { Total } \\
\text { (\% of Total) }\end{array}$ & $\begin{array}{r}833 \\
(1.03)\end{array}$ & $\begin{array}{l}1,750 \\
(2.16)\end{array}$ & $\begin{array}{l}47,169 \\
(58.32)\end{array}$ & $\begin{array}{l}13,902 \\
(17.19)\end{array}$ & $\begin{array}{l}1,034 \\
(1.28)\end{array}$ & $\begin{array}{l}4,162 \\
(5.15)\end{array}$ & $\begin{array}{l}5,244 \\
(6.48)\end{array}$ & $\begin{array}{l}6,779 \\
(8.38)\end{array}$ & $\begin{array}{r}80,873 \\
(100.00)\end{array}$ & (100.00) \\
\hline
\end{tabular}

Unit: 1,000 US dollar.

Table 5. Outcomes of sensitivity analyses on estimated total costs of hepatitis A infections

\begin{tabular}{|c|c|c|c|c|c|c|c|c|c|c|}
\hline & \multicolumn{8}{|c|}{ Clinical pathways of hepatitis A infections } & \multirow{2}{*}{ Total } & \multirow{2}{*}{$\begin{array}{l}\text { Difference with } \\
\text { base case (\%) }\end{array}$} \\
\hline & 1 & $\|$ & III & IV & V & $\mathrm{VI}$ & VII & VIII & & \\
\hline Baseline value case & 833 & 1,750 & 47,169 & 13,902 & 1,034 & 4,162 & 5,244 & 6,779 & 80,873 & - \\
\hline Sensitivity analysis 1 & 833 & 1,750 & 47,285 & 1,873 & 1,034 & 4,162 & 5,244 & 6,779 & 68,960 & -14.7 \\
\hline Sensitivity analysis 2 & 833 & 1,750 & 47,052 & 25,931 & 1,034 & 4,162 & 5,244 & 6,779 & 92,786 & 14.7 \\
\hline Sensitivity analysis 3 & 833 & 1,750 & 47,169 & 13,902 & 1,340 & 5,392 & 2,622 & 3,390 & 76,397 & -5.5 \\
\hline Sensitivity analysis 4 & 833 & 1,750 & 47,169 & 13,902 & 729 & 2,933 & 7,865 & 10,169 & 85,349 & 5.5 \\
\hline Sensitivity analysis 5 & 833 & 1,750 & 47,285 & 1,873 & 1,340 & 5,392 & 2,622 & 3,390 & 64,484 & -20.3 \\
\hline Sensitivity analysis 6 & 833 & 1,750 & 47,052 & 25,931 & 729 & 2,933 & 7,865 & 10,169 & 97,262 & 20.3 \\
\hline
\end{tabular}

Unit: 1,000 US dollar.

Sensitivity analysis $1 ; 50 \%$ of base value on fatality of hepatitis A infection.

Sensitivity analysis 2; $150 \%$ of base value on fatality of hepatitis A infection.

Sensitivity analysis $3 ; 50 \%$ of base value on transplantation probability in fulminant hepatitis A infection.

Sensitivity analysis 4; $150 \%$ of base value on transplantation probability in fulminant hepatitis A infection.

Sensitivity analysis 5 ; sensitivity analysis $1+$ sensitivity analysis 3 .

Sensitivity analysis 6; sensitivity analysis $2+$ sensitivity analysis 4 .

The total cost incurred in 2008 because of hepatitis A distributed by age group is presented in Table 4 . In the total cost distribution by age group, the 30-39 age group incurred the highest cost at $39.4 \%$ of all costs. Costs incurred by people aged $20-49$ were $87.4 \%$ of the total cost.

\section{Sensitivity analysis results}

Sensitivity analysis results are presented in Table 5 . When both the fatality of a hepatitis A infection and the probability of transplantation increased by $50 \%$ (sensitivity analysis 6 ), the total cost of hepatitis A infections was \$97,262,000, 20.3\% higher than the baseline analysis. When the probability of fatality from a hepatitis A infection and that of transplantation decreased to $50 \%$ of the baseline (sensitivity analysis 5), the total cost of hepatitis A infections was calculated at \$64,484,000, 20.3\% lower than the baseline analysis. Change in the fatality level of non-fulminant hepatitis A had a greater influence on the total cost than the change in transplantation probability did.

\section{DISCUSSION}

The present study estimated the economic costs of hepatitis A in South Korea in 2008 by an incidence-based approach using NHI claims data. The number of hepatitis A incidences in 2008 was 30,240. From a socioeconomic perspective, the total cost of the disease was $\$ 80,873,000$. Medical and non-medical direct costs respectively represented $45.1 \%$ and $11.1 \%$ of total costs. Indirect costs were $43.8 \%$ of total costs. The $20-39$ age group constituted $71.3 \%$ of the total number of incidences and $74.6 \%$ of the socioeconomic costs. The cost per case of hepatitis A was calculated to be $\$ 2,674$, which is lower than that of other dis- 
eases (e.g., cancer, stroke, asthma, or injury) reported in South Korea $[16,17,26,28]$. Compared to other digestive diseases, the cost of hepatitis A is higher than that of rotavirus (another digestive infectious disease) and is lower than that of irritable bowel syndrome $[29,30]$. The total societal cost of the rotavirus in South Korea in 2005 including indirect costs was reported to be approximately $\$ 13,300,000$. Accounting for the rise in CPI, the total societal cost of rotavirus in 2008 was $\$ 14,600,000$. Comparatively, the total social cost of hepatitis A was approximately 5.5 times higher. Furthermore, the total societal cost of irritable bowel syndrome in 2008 was $\$ 585,400,000,7.2$ times higher than that of hepatitis A.The portions of the total costs of rotavirus and irritable bowel syndrome captured by indirect costs were $5 \%$ and $25 \%$, respectively, markedly lower than those of hepatitis A (44\%).

The 30,240 cases of hepatitis A incidences in 2008 found through the present study were confirmed solely through primary and secondary diagnostic codes in the claims data of the NHI. The claims data can influence the number of incidences and disease costs depending on how medical institutions report cases of hepatitis A to National Health Insurance Corporation. According to our unpublished data, there was no significant difference between the number of hepatitis A incidences identified through medical records from 2002 to 2008 in 11 general-hospital-level medical institutions (3,081 cases) and those identified from the NHI claims data (2,928 cases) for the same period. Thus, we determined that it was feasible to use the number of hepatitis A incidences identified through the NHI claims data as the number of hepatitis A incidences [31]. However, because we could not confirm how medical institutions other than general hospitals recorded hepatitis A cases, additional studies should be conducted in the future to provide a more accurate estimate of the number of hepatitis A incidences.

The total societal cost of hepatitis A in South Korea in 2008 was estimated to be $0.008 \%$ of the gross domestic product (GDP) of South Korea and $0.12 \%$ of national health expenditures. In a US study published in 2000 , the total societal cost of hepatitis A in the US was estimated to be $\$ 48,880,000,0.006 \%$ of the US GDP and $0.044 \%$ of national health expenditures that year. The total societal cost of hepatitis A in the US was also relatively lower than that of South Korea [32]. Such statistics can partially be explained by the fact that the number of Korean hepatitis A incidences reported in the present study was approximately two times greater than that of the number reported in the aforementioned US study. It was also reported that the portion of the total costs of hepatitis A captured by indirect costs was $44 \%$ in South Korea, whereas it was $74 \%$ in the US, relatively conservative estimate. A lack of data on countries other than the US meant that we could not directly compare the total societal cost of hepatitis A in these countries with such costs in South Korea as calculated in the present study.

As hepatitis A infections occurring in the age group 20-39 constitutes over $70 \%$ of the total number of incidences and societal costs, an intervention strategy to lower the total societal cost of hepatitis A should involve the management of hepatitis A in young adults. Although prioritizing an effective hepatitis A vaccination of young adults initially seems like an ideal solution, a national pediatric vaccination effort has been reported to inhibit transmission by asymptomatic patients and induce herd immunity to reduce the number of adult hepatitis A incidences in a short time. Thus, additional studies must be conducted to evaluate an optimal vaccination strategy to allow maximum effectiveness given the situation in South Korea [33-36]. It is also necessary to explore the number of hepatitis A incidences in young adults by consistently monitoring patient occurrence patterns, risk factors, and the cost of hepatitis A in the country.

When interpreting the results of the present study, the estimated cost of hepatitis A was conservative in many respects. As the cost and number of hepatitis incidences were estimated by extracting NHI claims data that had disease codes associated with hepatitis A, undiagnosed cases of non-specific hepatitis A and hepatitis A reported as generic hepatitis to avoid cumbersome reporting procedures were excluded from the estimated results of the disease cost in this study. With respect to the cost of productive losses, the number of non-productive days (i.e., absent days) other than inpatient days and outpatient visit days could not be estimated because of a lack of relevant data. For direct and indirect costs, the cost of reduced quality of life because of hepatitis A and psychological costs could not be estimated because of the difficulty of converting the two aforementioned costs into a monetary value. Finally, the present study failed to consider the cost of public health measures in case of a hepatitis A outbreak such as epidemiological investigations. Such limitations suggest that the results of the present study may have underestimated the actual costs of hepatitis A infections. Furthermore, even if fatalities caused by hepatitis A and the transplantation probability of a fulminant hepatitis patient changed by $50 \%$ of the base value, the total societal cost of the disease changed by $20 \%$, indicating that the two aforementioned factors have limited influences on the study results.

Furthermore, there were limitations in the data to construct the cost and incidence rate for each clinical pathway by gender. Thus, the study result could not be rendered with respect to gender. Even in the case of indirect costs, we did not differentiate the data by gender and calculated the indirect cost based on the average data of both genders. Considering the fact that the number of hepatitis A incidences in males was approximately $50 \%$ higher than that of females [37], we predict the total indirect costs estimated through the present study to be a slightly conservative estimated. 
Another limitation of the study is that we did not use a consistent method to calculate the cost and number of hepatitis A incidences when estimating the total societal cost of hepatitis A. We also used many assumptions in our calculations. However, such limitations are difficult to avoid in burden of disease studies given the lack of data that show the overall economic burden of the disease. In addition, because factors that may potentially have a strong influence on the study result were analyzed through sensitivity tests, we believe that we have addressed our shortcomings accordingly. The fact that the number of fatalities caused by hepatitis A and the number of liver transplantations estimated in the study were estimated through its research design is another cautionary note regarding the interpretation of the study results.

In the future, if we accounted for other hepatitis A costs not captured in the present study, we would have a more accurate estimate of the real costs of hepatitis A. The total societal costs of hepatitis A estimated in the study were lower than those of chronic diseases with high prevalence, including general cardiovascular diseases and cancer. However, the indirect cost of hepatitis A because of productive loss from premature death was shown to be relatively high. Thus, reducing indirect rather than direct costs would be more significant when implementing an intervention strategy for hepatitis A. In addition, the study's clear presentation of the benefits of preventing a single case of hepatitis A will be useful in aiding communication among experts, public health authorities, and citizens.

\section{ACKNOWLEDGEMENTS}

This work was supported by grants from the Korea Centers for Disease Control and Prevention.

\section{CONFLICT OF INTEREST}

The authors have no conflicts of interest to declare for this study.

\section{SUPPLEMENTARY MATERIAL}

Supplementary material is available at http://www.e-epih.org/.

\section{REFERENCES}

1. Thomas HC, Lemon S, Zuckerman AJ. Viral hepatitis. 3rd ed. Massachusetts: Wiley-Blackwell; 2005, p. 92-125.
2. World Health Organization. Hepatitis A [cited 2014 Aug 9]. Available from: http:/www.who.int/csr/disease/hepatitis/whocdscsredc2007/en/.

3. Jacobsen KH, Koopman JS. Declining hepatitis A seroprevalence: a global review and analysis. Epidemiol Infect 2004;132:1005-1022.

4. Jacobsen KH, Koopman JS. The effects of socioeconomic development on worldwide hepatitis A virus seroprevalence patterns. Int $\mathrm{J}$ Epidemiol 2005;34:600-609.

5. Hendrickx G, Van Herck K, Vorsters A, Wiersma S, Shapiro C, Andrus $\mathrm{JK}$, et al. Has the time come to control hepatitis A globally? Matching prevention to the changing epidemiology. J Viral Hepat 2008;15 Suppl 2:1-15.

6. Song YB, Lee JH, Choi MS, Koh KC, Paik SW, Yoo BC, et al. The age-specific seroprevalence of hepatitis A virus antibody in Korea. Korean J Hepatol 2007;13:27-33 (Korean).

7. Kang JH, Lee KY, Kim CH, Sim D. Changing hepatitis A epidemiology and the need for vaccination in Korea. Asian Pac J Allergy Immunol 2004;22:237-242.

8. Kang CI, Choi CM, Park TS, Lee DJ, Oh MD, Choe KW. Incidence and seroprevalence of hepatitis A virus infections among young Korean soldiers. J Korean Med Sci 2007;22:546-548.

9. Sohn YM, Rho HO, Park MS, Park JH, Choi BY, Ki M, et al. The changing epidemiology of hepatitis $\mathrm{A}$ in children and the consideration of active immunization in Korea. Yonsei Med J 2000;41:34-39.

10. Korea Centers for Disease Control and Prevention. Viral hepatitis statistics: communicable disease sentinel surveillance [cited 2009 Sep 20]. Available from: http://stat.cdc.go.kr/ (Korean).

11. Lee D, Cho YA, Park Y, Hwang JH, Kim JW, Kim NY, et al. Hepatitis a in Korea: epidemiological shift and call for vaccine strategy. Intervirology 2008;51:70-74.

12. Jeong SH. Current status and vaccine indication for hepatitis A virus infection in Korea. Korean J Gastroenterol 2008;51:331-337 (Korean).

13. Tarricone R. Cost-of-illness analysis. What room in health economics? Health Policy 2006;77:51-63.

14. Rice DP. Cost-of-illness studies: fact or fiction? Lancet 1994;344:15191520.

15. Park CS, Kang HY, Kwon I, Kang DR, Jung HY. Cost-of-illness study of asthma in Korea: estimated from the Korea national health insurance claims database. J Prev Med Public Health 2006;39:397-403 (Korean).

16. Park K, Lee JS, Kim Y, Kim YI, Kim J. The socioeconomic cost of injuries in South Korea. J Prev Med Public Health 2009;42:5-11 (Korean).

17. Lim SJ, Kim HJ, Nam CM, Chang HS, Jang YH, Kim S, et al. Socioeconomic costs of stroke in Korea: estimated from the Korea national health insurance claims database. J Prev Med Public Health 2009;42:251-260 (Korean)

18. Yang BM, Kim CH, Kim JY. Cost of chronic hepatitis B infection in South Korea. J Clin Gastroenterol 2004;38:S153-S157.

19. Bauch CT, Anonychuk AM, Pham BZ, Gilca V, Duval B, Krahn MD. Cost-utility of universal hepatitis A vaccination in Canada. Vaccine 2007;25:8536-8548.

20. Kim JM, Lee YS, Lee JH, Kim W, Lim KS. Clinical outcomes and predictive factors of spontaneous survival in patients with fulminant hepatitis A. Korean J Hepatol 2008;14:474-482 (Korean).

21. Jacobs RJ, Greenberg DP, Koff RS, Saab S, Meyerhoff AS. Regional variation in the cost effectiveness of childhood hepatitis A immunization. Pediatr Infect Dis J 2003;22:904-914.

22. Kim J, Lee H, Jeong H, Survey on out-of-pocket payment of national health insurance, 2007. Seoul: National Health Insurance Corporation; 2008, p. 49-59 (Korean). 
23. National Health Insurance Corporation. 2007 national health insurance statistical yearbook. Seoul: National Health Insurance Corporation; 2008, p. 180-181 (Korean).

24. Ha HS. National health insurance coverage and household burden of liver transplantation. Korean J Hepatol 2005;11:S111-S114 (Korean) (author's translation).

25. Jung YH, Ko S. The socioeconomic cost of diseases in Korea. J Prev Med Public Health 2006;39:499-504 (Korean).

26. Kim J, Hahm MI, Park EC, Park JH, Park JH, Kim SE, et al. Economic burden of cancer in South Korea for the year 2005. J Prev Med Public Health 2009;42:190-198 (Korean).

27. Korean Statistical Information Service. Employment, labor and wage [cited 2009 Sep 1]. Available from: http://kosis.kr/statisticsList/statisticsList_01List.jsp?vwcd=MT_ZTITLE\&parmTabId=M_01_01\#Su bCont (Korean).

28. Park CS, Kang HY, Kwon I, Kang DR, Jung HY. Cost-of-illness study of asthma in Korea: estimated from the Korea national health insurance claims database. J Prev Med Public Health 2006;39:397-403 (Korean).

29. Yang BM, Jo DS, Kim YH, Hong JM, Kim JS. The societal cost of rotavirus infection in South Korea. Korean J Pediatr 2008;51:977986 (Korean).

30. Choi MG, Jeong HG, Jang BH, Kim YH, Nam MH, Park SY, et al. Calculation of the burden of irritable bowel syndrome, national evidence based healthcare collaborating agency; 2011 [cited 2014 Jun
22]. Available from: http://www.neca.re.kr/center/researcher/report view.jsp?boardNo $=\mathrm{GA} \&$ seq $=3 \& q=626 \mathrm{f} 6172644 \mathrm{e} 6 \mathrm{f} 3 \mathrm{~d} 4741$ (Korean). 31. Ki MR, Park MR, Yoo WS, Jeong BG, Park JK, Choi BY, et al. Economic analysis of vaccination and development of guidelines for control of hepatitis A virus infection, and epidemiologic analysis and development of control strategy of hepatitis $\mathrm{C}$ virus infection. Seoul: Korea Centers for Disease Control and Prevention; 2009, p. 71 (Korean).

32. Berge JJ, Drennan DP, Jacobs RJ, Jakins A, Meyerhoff AS, Stubblefield W, et al. The cost of hepatitis A infections in American adolescents and adults in 1997. Hepatology 2000;31:469-473.

33. Dagan R, Leventhal A, Anis E, Slater P, Ashur Y, Shouval D. Incidence of hepatitis A in Israel following universal immunization of toddlers. JAMA 2005;294:202-210.

34. Wasley A, Samandari T, Bell BP. Incidence of hepatitis A in the United States in the era of vaccination. JAMA 2005;294:194-201.

35. Vacchino MN. Incidence of hepatitis A in Argentina after vaccination. J Viral Hepat 2008; 15 Suppl 2:47-50.

36. Domínguez A, Oviedo M, Carmona G, Jansá JM, Borrás E, Salleras $\mathrm{L}$, et al. Epidemiology of hepatitis A before and after the introduction of a universal vaccination programme in Catalonia, Spain. J Viral Hepat 2008;15 Suppl 2:51-56.

37. Korea Centers for Disease Control and Prevention. Disease web statistics system [cited 2009 Sep 1]. Available from: http://is.cdc.go.kr/ nstat/index.jsp (Korean). 